\title{
Extracellular Matrix and Colorectal Cancer: How Surrounding Microenvironment Affects Cancer
}

\section{Cell Behavior?}

Sara Crotti ${ }^{1}$, Martina Piccoli ${ }^{1}$, Flavio Rizzolio ${ }^{3}$, Antonio Giordano ${ }^{4,5}$, Donato Nitti $^{2}$ and Marco Agostini ${ }^{1,2}$

1 Istituto di Ricerca Pediatrica- Città della Speranza, Corso Stati Uniti 4, 35127 Padova, Italy.

2 First Surgical Clinic Section, Department of Surgical, Oncological and Gastroenterological Sciences, University of Padua, Via Nicolo Giustiniani 2, 35128 Padova, Italy.

3. Department of Translational Research, IRCCS-National Cancer Institute, Aviano, Italy.

4. Sbarro Institute for Cancer Research and Molecular Medicine, Center for Biotechnology, College of Science and Technology, Temple University, Philadelphia, PA, USA.

5. Department of medicine, surgery and neuroscience, University of Siena, Italy.

\section{Running title:}

ECM and colorectal cancer

\section{Key words:}

Extracellular matrix; secretome; colorectal cancer; desmoplasia.

Corresponding author:

Marco Agostini, PhD

Surgical Clinic, Department of Surgical, Oncological and Gastroenterological Sciences, University of Padova, Via Giustiniani 2, 35128 Padova, Italy.

Tel: +39 049-8212069, Fax: +39 049-651891, e-mail: m.agostini@unipd.it 


\begin{abstract}
Colorectal cancer (CRC) whit more than a million of new cases per year is one of the most common registered cancers worldwide with few treatment options especially for advanced and metastatic patients.

The tumor microenvironment is composed by extracellular matrix (ECM), cells and interstitial fluids. Among all these constituents, in the last years an increased interest around the ECM and its potential role in cancer tumorigenesis is arisen. During cancer progression the ECM structure and composition became disorganized, allowing cellular transformation and metastasis.

Up to now, the focus has mainly been on the characterization of CRC microenvironment analyzing separately structural ECM components or cell secretome modifications. A more extensive view that interconnects these aspects should be addressed. In this review, biochemical (secretome) and biomechanical (structure and architecture) changes of tumor microenvironment will be discussed, giving suggestions on how these changes can affect cancer cell behavior.
\end{abstract}




\section{Introduction}

Colorectal cancer (CRC) is the third most common cancer in both sex with more than a million of new cases per year and more than 500.000 deaths registered worldwide [1]. If diagnosed at early stage (stages $0, \mathrm{I}, \mathrm{II}$, and III), CRC is in general highly treatable with surgery. For patients with stage III and some with stage II, the chemotherapy is practiced after surgery in order to increase the therapeutic response [2]. In the clinical practice, the established staging models for CRC such as the TNM [3] and the tumor localization are based on morphological, histopathological and clinical criteria, and should provide adequate information on the tumor metastatic potential directing clinicians to plan an adequate therapeutic strategy. Possible new markers may result from the study of extracellular matrix (ECM) components, particularly those that provide the evidence of aggressiveness. These new markers could ameliorate the actual clinical staging differentiating patients with an aggressive CRC from those with more indolent disease.

In the last decades, an increased interest around the ECM and its potential role in cancer tumorigenesis is arisen [4-5]. The ECM, with its distinctive biochemical and biomechanical properties, is one of the proximal structures that tumor cells of epithelial origin must destroy in order to permit invasion and cell migration. The ECM structure and composition became disorganized during cancer progression, promoting itself cellular transformation and metastasis. Indeed the ECM microenvironment, or niche, plays an important role in regulating cell behavior. This concept was initially true in the field of developmental biology, and in the past 20 years was also demonstrated for cancer development and biology [6-7]. Several components of the niche participate to cancer progression, especially inflammatory cells, such as T cells and myeloid suppressor cells, which fail to exercise antitumor effector functions, and co-operate with cancer cells to promote tumor growth [8]. Together with cellular component, recent progress highlighted the ECM importance in cancer progression [9-12]. During embryonic development and organ homeostasis, ECM is tightly controlled with the production, degradation, and remodeling of the major protein components. The disruption of this fine control disorganizes the ECM, promoting abnormal cell behavior, tumor-associated angiogenesis and inflammation, and finally leads to generation and progression of cancer microenvironment. In this review, we describe how biochemical and biomechanical changes could drive tumor progression and aggressiveness, with suggestions on how these changes could be choosen as therapeutic targets for cancer treatment. 


\section{The colon ECM structure}

The normal colon ECM structure is reported in Figure 1. The regular and organized structure keeps under control cellular processes such as growth, death, adhesion, migration, and differentiation. Its function is to maintain homeostasis and to orchestrate tissue repair in case of injury or damage.

Normal tissue
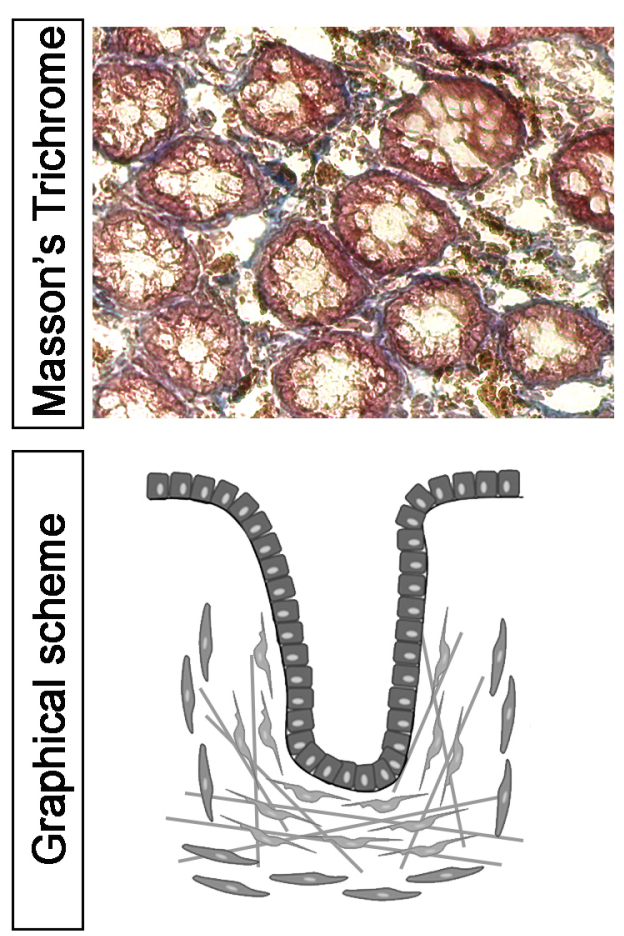

Isotropic arrangement

\section{Cancer tissue}
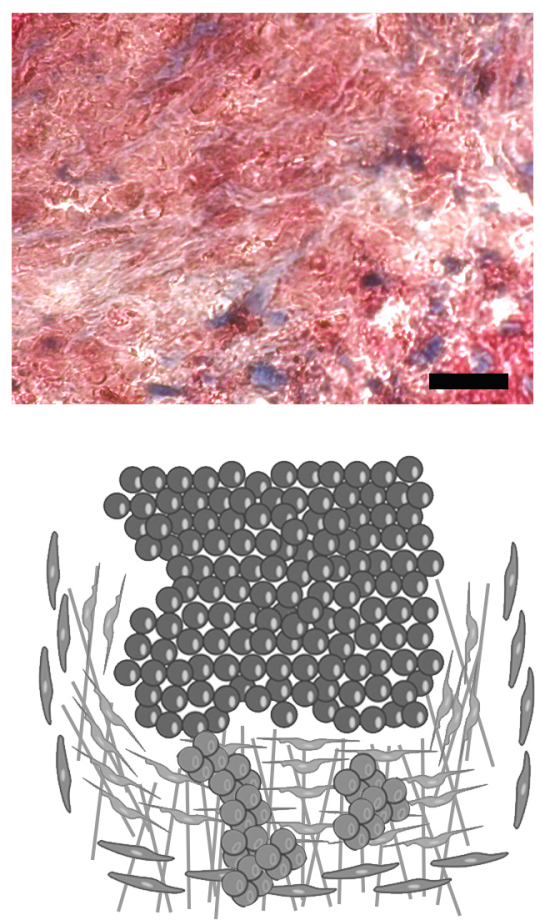

Anisotropic arrangement (Desmoplasia)

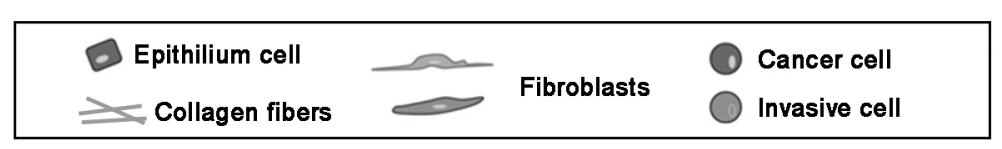

Figure 1. Schematic representation of normal and colon cancer tissue. Upper panel: Masson's Trichrome staining showing the connective tissue (blue), nuclei (dark red/purple), and cytoplasm (red/pink). Lower panel: graphical scheme highlighting the transition from the normal colon (Isotropic) mucosa to the cancer (anisotropic) microenvironment.

Colonic epithelial cells exert a physical barrier with absorptive and exocrine functions. These cells possess a polarized structure in which is recognizable an apical pole, two lateral surfaces forming inter-cellular connections and a basal surface anchored to the basement membrane (BM). The BM is a specialized form of ECM separating the colon mucosa from its submucosa. The BM proteins 
are synthesized by both the epithelial and the mesenchymal cells under physiological conditions [13-14] and rearranged to a characteristic sheet-like structure of $100-300 \mathrm{~nm}$ of thickness. The main constituent of $\mathrm{BM}$ is the Collagen IV, a network-forming collagen composed by a trimerization of alpha chains (two $\alpha 1$ - and one $\alpha 2$-chain) encoded by six genes (COL4A1-COL4A6) and other proteins such as the proteoglycan perlecan and the glycoproteins laminin, fibronectin and nidogen [15]. From a structural point of view, the stromal ECM is constituted by similar components already present in the BM, but Collagen IV is substituted by Collagen I (COL1A1,COL1A2), this last forming a 3D structure thanks to its fibrillar proprieties. The Collagen I is produced by resident fibroblasts and, differently from Collagen IV, no disulphide bridge are present, thus providing a less rigid structure to the ECM with respect the BM. For several years the ECM was considered a solely filling and inert substrate, but now its active role in carcinogenesis is clear [16-17].

Beside the structural proteins, other constitutive elements of ECM are those proteins and molecules secreted by tumor and stroma cells and "collected" under the term secretome. The classical way of secretion is based on soluble proteins released after the signal peptide cleavage, however also non-classical ways have been identified in tumor secretome including exosomes[1819] and microvesicles secretion [20]. Recently, Naba et al. [21] introduced the term matrisome to gather all ECM components by the in silico prediction of putative ECM proteins. Further proteomics data on extracted ECM samples confirmed their classification. Under this term, more than one hundred of putative ECM proteins have been categorized in two distinct groups: i) structural core matrisome and ii) matrisome-associated proteins including secreted factors, proteases and protein families such as mucins, galectins and semaphorins [21].

\section{Changes in ECM structure in colorectal cancer}

The tumor mass in CRC, like every other tumor, has three basic components: i) the parenchyma, i.e. the proliferating neoplastic cells and the supportive stroma ii) the tumor associated cells (TAM, tumor associated macrophages and the activated fibroblasts) and iii) the blood vessels.

As mentioned before, under physiological and non-pathological conditions the ECM, composed of BM and adjacent parenchyma, possesses isotropic arrangement of fibrillar protein components. An orderly ECM confers to the matrix unique spatial, biochemical and biomechanical properties that are essential for regulating cell behavior and tissue homeostasis. On the contrary, 
an organized, anisotropic arrangement of ECM fibers is a recognized hallmark of a pathological microenvironment [22-23] and the term desmoplasia is used to define the abundant collagenous stroma surrounding parenchymal cells that is deposited after BM degradation. It is important to underline that the BM degradation is not only a passive event, but actively participate to the tumoral progression releasing angiogenic, growth-stimulating, and chemotactic factors embedded within the BM [24-26]. All these factors affect the tumor microenvironment, regulating tumor growth, angiogenesis, and cell migration. This is the case of laminin-332 (formerly known as laminin-5) protein, which is homogeneously present in the BM in the normal intestinal mucosa. The laminin-332 degradation products activate the EGF receptor pathway causing a diminished cell-matrix adhesion, ultimately leading the migration enhancement [27-29]. The loss of BM integrity is one of the most common ECM marker studied up-to now and recently reviewed by Mylonas et al. [30], who pointed out that in primary CRC tumors the discontinuity of the BM is correlated to a higher metastatic potential [31] and poor patients' survival rate [32].

The newly deposited collagen replace the proteolitically degraded ECM proteins by secreted proteases. In the case of breast cancer, this structural evolution is known as tumorassociated collagen signatures (TACS). Three levels have been identified denoting changes in fibers organization during the tumoral progression from nonpalpable (TACS 1) to non-invasive (TACS 2) and metastasis (TACS 3) [22]. Such a change causes local cell migration that is predominantly oriented along radial aligned collagen fibers, facilitating the tumoral invasion. Recently, it has been demonstrated that a similar event occurs also in CRC: in the healthy colon, collagen fibers are disposed in the epithelium-stroma interface whit an angle of $\sim 10^{\circ}$, while in the adenocarcinoma collagen fibers are thicker and showed an averaged angled disposition around the $50^{\circ}$ with respect to interface [33]. In another work, changes in collagen density and alignment have been demonstrated in polyps with high-grade dysplasia (HGD) and malignant samples. With respect to the normal colon tissue, in which are present aligned collagen fibers, the HGD revealed the presence of misaligned collagen fibers. The resultant changes in the ECM of malignant samples is a more dense and ordered collagen fiber deposition [34] suggesting a pivotal role of collagen in malignant tissue transformation.

Collagen degradation during stroma remodeling releases several fragmented peptides which can be easily detected in plasma and urines [35] and two peculiar peptides of type I Collagen are indicative of the degradation process: the $\mathrm{N}$ - and $\mathrm{C}$-telopeptides. Beside these, other fragments from the $\mathrm{N}$ - and the C-terminal regions, the PINP (the amino $\mathrm{N}$-terminal propeptide) 
and the PICP (the carboxy C-terminal propeptide) are indicative of collagen neo-synthesis [36]. Both the PICP and the C-telopeptide levels in serum of CRC patients (stages I-IV) have been found increased with respect to the control group [37], indicating the presence of both collagen degradation (tumoral mass expansion) and deposition (ordered fiber deposition). As a consequence of ECM remodeling, triple-helical region fragments have been detected and quantified in urine of patients affected by CRC with a sensitivity of $88 \%$ and a specificity of $88 \%$ [35].

The liver is the most frequent site of metastasis from primary colorectal cancer [38]. With difference to colon mucosa, the liver is enriched in type IV Collagen fibers mainly located in the sinusoids and, together with perlecan and laminin is the main constituent of organized BM [39]. It is know that Collagen IV plasma levels are generally increased in liver diseases associated with hepatic fibrogenesis and fibrosis [40]. Because of a similar remodeling process occurs both in primary cancer and in distant metastasis, the Collagen IV can be used as prognostic marker of disease progression [41-42]. As a proof of this, in the plasma of patients presenting hepatic metastasis, type IV Collagen increases compared to non-metastatic CRC patients and healthy controls. Moreover, the ECM remodeling process combined with the increased expression of the $\alpha 1$ - and $\alpha 2$ - chains of type IV Collagen has been observed in the stroma of hepatic metastasis [43]. A deeper observation evidenced that type IV Collagen plasma levels were also correlated to the therapeutic response and pathology progression showing a decrease during chemotherapy and an increase in consequence of disease progression [43]. The prognostic value of hepatic Collagen IV is increased by the concomitant detection of other ECM proteins such as tenascin- $\mathrm{C}$, fibronectin, and laminin. This composition has been highlighted to be peculiar of 'non-capsular' tumors and their detection, as well as the presence of alpha-smooth muscle actin positive myofibroblasts, was associated with a shorter median survival with respect to patients with "capsular" metastasis [44].

Beside collagens, other ECM proteins are deregulated in CRC cancer. Evidence of proteins alteration can be obtained by the comparative analysis of colon-purified matrices in normal and tumoral tissues in order to find other specific ECM signatures associable to cancer progression [4546]. The technical procedure used to obtained ECM purified proteins was based on the assumption of their insolubility in traditional buffers, thus offering the advantage of sequentially separate and remove cellular and nuclear proteins from that of ECM. Despite this consideration, the major part of the identified proteins (1062 proteins) still were from cellular compartment and relatively few proteins were associated with ECM (163 proteins) [45]. Nevertheless, the paired 
analysis of three primary metastatic colon cancers and their hepatic metastasis proved that 23 ECM-related proteins were in common for both tissues. Beside these, 37 and 7 proteins were exclusively present in the primary tumor and the metastasis, respectively. Tumor-derived proteins were mainly structural proteins such as ECM glycoproteins, collagens, and proteoglycans and other less abundant ECM-related proteins such as ECM remodeling enzymes and ECM-associated secreted factors. As expected, proteases were peculiar of primary colon tumor: ADAM 9, 10, TSL1 and MMP1, 2, 9, 11, and 12 have been found solely in colon tumor [45] and not in the metastasis, suggesting their role in the migration process. In another paper, the paired biopsies from tumor and its normal counterpart were obtained from 13 patients. Fifty-six differentially expressed proteins have been identified in the insoluble tissue fraction, after the extraction of lipids and soluble proteins. The digested peptides from ECM fraction were analyzed using a nano-ESI source by means of label-free quantitation approach (e.g. solely based on measurements of observed peptide ion peak intensities). The obtained data highlighted that 31 proteins related to cellular cytoskeletal filaments were up-regulated (fold change $>1.2$ ), and 25 proteins related to ECM were down-regulated (fold change $<0.8$ ). The down-regulated proteins included myosin, keratin, and collagen; in particular the three chains $(\alpha 1, \alpha 2$ and $\alpha 3)$ of type VI Collagen were among the lower abundant proteins in cancer tissues [46].

\section{Changes in ECM architecture in colorectal cancer}

Directly linked with the above mentioned changes of biochemical properties, another outstanding characteristic of the ECM is its elasticity, that ranges from soft and compliant to stiff and rigid, and contributes to the development of disease. Increased matrix stiffness is typical of most solid tumors and these changes can be due to different mechanism. For example, excess activities of lysyl oxidase (LOX), an ECM-modify enzyme that among all ECM proteins cross-links especially collagen fibers, could increase tissue stiffness. Up-regulation of LOX expression has been found in several cancers, including CRC, and has been associated with poor prognosis [47-48]. The LOX-mediated collagen cross-linking, in in vitro and in vivo models of CRC results in increased tissue stiffness and activation of the FAK/SRC signaling. As a consequence, cells expressing high levels of enzymatically active LOX protein have an increased capacity to proliferate, invade and metastasize [49], data that support the correlation between stiffer stroma and cancer aggressiveness. 
When ECM became stiff, with formation of cross-linked collagen bundles, its biomechanical properties change, and cells respond by exerting markedly different kinds of attitude, as demonstrated by recent studies on mechanotransduction [50]. Balancing cell proliferation and apoptosis is essential to proper tissue function. A disruption in this equilibrium can result in tumorigenesis if there is inadequate apoptosis coupled to uncontrolled cell proliferation. The Hippo pathway, which has been uncovered for the first time in Drosophila genetic screens, is a potent regulator of tissue homeostasis by controlling cell growth, division, and apoptosis. Recently, two fundamental Hippo pathway's elements, the Yes-associated protein (YAP) and its paralogue TAZ, have been shown to be directly involved in the mechanisms of response to structural changes in the cell microenvironment [51-52]. Mechanical stimuli, such as increase substrate stiffness, can trigger nuclear translocation of YAP/TAZ, initiating their interaction with other transcription factors to control cell proliferation and motility [53]. In cancer environment, YAP and TAZ over-expression induces cell proliferation and epithelial to mesenchymal transition (EMT), and reduces apoptosis and contact inhibition [54-55]. YAP is associated with clear cell ovarian tumors, an ovarian malignancy subtype with poor prognosis [56], and has been shown to play an oncogenic role in esophageal squamous cell carcinoma [57]. TAZ is directly involved in the progression of breast [58-59] and non-small cell lung cancer [60]. There are evidences that YAP and TAZ play an important role also in colon cancer: YAP has been found over expressed in 68 of 71 human colon cancer analyzed biopsies and in 30 of 36 colon cancer-derived cell lines, suggesting that this protein is likely to be an important driver in this malignancy [61].

Despite recent advances in the field, it is not clear yet if changes in stiffness can play a causative role in cancer pathogenesis. In breast cancer has been demonstrated that ECM deregulation is one of the primary inducers of tumorigenesis [11], suggesting that this type of mechanism can be implicated in tumor initiation also in other tissues.

\section{Changes in colorectal cancer secretome}

Secreted proteins play important roles in homeostasis, immune response, development, proteolysis, adhesion, and ECM organization. Moreover, in a living organism secretome is highly dynamic, and its composition changes during cell differentiation [62] or in response to various pathologies [63] and/or environmental stimuli [64-65]. In the last decades, the tumor secretome has been judged a promising source for biomarker discovery and it has been extensively investigated [66]. The tumor microenvironment is mainly composed by cells, ECM and interstitial 
fluid (IF); this last is enriched in tumor-derived proteins secreted by classical (e.g. ER/Golgi apparatus mediated) or non-classical (endosomial recycling, active protein transport, membrane translocation and exosomes) pathways [67].

It has been largely demonstrated that not only the tumoral cells, but the cancer-associated fibroblasts (CAF), the inflammatory cells (e.g., TAM) and the endothelial cells can also actively participating to the secretome composition in the tumor microenvironment. This causes a differential expression of proteases and cytokines in tumor cells compared with tumor-associated stroma [68-69]. During tumor invasion and metastasis, tumor cells directly secrete degradative enzymes or induce the host to produce proteolytic enzymes to degrade ECM. Proteolytic enzymes are major players in the breakdown and reconstruction of ECM in a wide of physiological and pathological processes. So great attention is paid on the aberrant expression and the predictive value of the proteolytic enzymes (and their inhibitors), such as: MMPs [70], plasminogen activation system [71], ADAMTSs [72] and cathepsins [73]. Table 1 summarized the changes in expression and proteins levels of these proteolytic enzymes observed in CRC. In particular, in CRC two key gelatinases (MMP-2 and MMP-9) and two key collagenases (MMP-1 and MMP-13) have been extensively investigated and a good review on this topic is already present [74]. The CAF produce and secrete growth factors and cytokines that promote tumor survival [75] and aggressiveness [76], while the recruited inflammatory cells secrete angiogenic growth factors, cytokines and other MMPs [77-78], which ensure the neoplastic progression and invasion. For instance, it has been demonstrated that the MMP-2 is mostly synthesized by the inflammatory infiltrated cells and only in a less extent by the tumoral cells itself [67]. In addition, endothelial cells can be activated by tumoral cells. The release of hypoxia-inducible factors (HIF) and vascular endothelial growth factor-A (VEGF-A) [79] by cancer cells stimulate the autocrine secretion of VEGF and angiopoietin [79-80] in endothelial cells, with consequent tumor angiogenesis and vasculogenesis.

Table 1: Overview of secreted proteolytic enzymes and their physiological inhibitors involved in the colorectal cancer (CRC). Legend: ADAMTS, a-disintegrin and metalloproteinase with thrombospondin motifs; MMP, matrix metalloproteases; TIMP, tissue inhibitor of metalloproteinases; uPA, urokinase-type Plasminogen Activator; tPA, tissue Plasminogen Activator; PAI, Plasminogen Activator Inhibitor.

\section{Recommended}

name:

ADAMTS-15

ADAMTS-18
Alternative name Changes in protein levels/gene expression

Decreased expression in colon cancer

Decreased expression inactivated in colon cancer
Ref. 


\begin{tabular}{|c|c|c|c|}
\hline Cathepsin B & APP secretase & Increased tumor tissue levels & {$[85-88]$} \\
\hline Cathepsin L1 & Cathepsin L & Increased tumor tissue levels & {$[87,89]$} \\
\hline MMP-1 & Collagenase-1 & Increased plasma levels and tumor tissue expression & {$[70,90-91]$} \\
\hline MMP-2 & Gelatinase A & $\begin{array}{l}\text { Increased tissue levels in tumor and metastasis } \\
\text { Decreased serum levels in } 72 \mathrm{CRC} \text { patients }\end{array}$ & $\begin{array}{l}{[70,92]} \\
{[93]}\end{array}$ \\
\hline MMP-7 & Matrilysin & $\begin{array}{l}\text { Increased expression and protein levels in liver } \\
\text { metastases samples }\end{array}$ & [94-96] \\
\hline MMP-9 & Gelatinase B & $\begin{array}{l}\text { Increased tissue and serum levels in tumor and liver } \\
\text { metastasis }\end{array}$ & {$[92,97-99]$} \\
\hline MMP-12 & Metalloelastase & Increased tissue levels in metastasis & $\begin{array}{l}{[68,100-} \\
101]\end{array}$ \\
\hline MMP-13 & Collagenase-3 & Increased tumor tissue levels & {$[102-105]$} \\
\hline \multirow[t]{2}{*}{ PAl-1 } & \multirow[t]{2}{*}{ Serpin E1 } & $\begin{array}{l}\text { Increased expression in stroma cells at tumor tissue } \\
\text { levels or in co-cultures }\end{array}$ & $\begin{array}{l}{[69,106-} \\
108]\end{array}$ \\
\hline & & Higher plasma levels & [109-110] \\
\hline PAl-2 & Serpin B2 & Increased expression at tumor tissue level & {$[110-111]$} \\
\hline TIMP-1 & & Increased plasma and tumor tissue levels in CRC patients & [112-114] \\
\hline TIMP-2 & & Decreased serum and tissue levels & {$[93,115]$} \\
\hline TIMP-3 & & Decreased tissue levels in CRC patients & {$[116-118]$} \\
\hline TIMP-4 & & $\begin{array}{l}\text { Increased levels in rectal cancer patients predict longer } \\
\text { survival }\end{array}$ & [119] \\
\hline uPA & & Increased tissue levels in colon and rectal cancer & $\begin{array}{l}{[71,109,} \\
111]\end{array}$ \\
\hline tPA & & Decreased tissue levels and activity in CRC patients & [120-122] \\
\hline
\end{tabular}

The secretome is an important source of biomarker discovery, since the IFs are relatively enriched in proteins otherwise not easily detectable at blood or plasma levels. As a proof of this, some authors provided the match of cell/tissue secretome with plasma levels of detected proteins and positively tested their clinical value as biomarkers in CRC [123-124]. Mass spectrometry-based proteomic approaches are the best way to investigate the secretome, since this technology leads to detect hundreds of potentially secreted proteins per analysis. To identify with confidence such a number of proteins, both pre-analytical and analytical issues are of fundamental importance. For instance, sample pre-fractionation before mass spectrometry analysis by means of gel electrophoresis (i.e. 1/2-DIGE or off-gel separations) [125] or proteins enrichment procedures [126-127] are usually performed to diminishing the ion suppression phenomena or to increase the 
low-abundance proteins concentration, respectively. Together with nano-ESI sources and high sensitive instrumentation, more than 2000 unique proteins have been identified in a single colon secretome sample [128]. Curiously, the final step of this workflow requires the reduction of data complexity by means of statistics [123] and bioinformatics [129], in order to pick-up few, but extremely significant proteins.

The analysis of secretome changes during the development and progression of CRC has been performed using different approaches. In Table 2, the comparison of biological source of secretome, the experimental procedures and the most interesting results obtained are reported. In the simplest protocols, cancer cell lines are cultured in traditional medium until confluence, then cultures are shifted into a serum-free medium for at least $20 \mathrm{~h}$, in order to reduce the contamination of non-endogenous proteins. Despite this approach minimize the sample complexity, the collected conditioned medium (CM) is an extreme simplification of what really occurs in vivo, not including all the other cells that participate to the secretome composition. Indeed, the co-cultures of colon cancer cells with CAF or TAM highlighted the dramatic changes in their secretome composition with respect to cancer cell cultured alone [78]. In fact, Kang et al. demonstrated in different co-culture of colon cancer cells lines (HCT116, WiDr, SW480, and RKO) and TAM cell lines (THP-1 and U937) that the latter cells cause the up-regulation of tumor cellderived MMP-2 and MMP-9, with increased tumoral invasiveness and migration with respect to single cultured cancer cell line [78].

Table 2: Overview of secretome studies in colorectal cancer in cells and tissues performed using mass spectrometry-based proteomic approach.

\section{cell tumor cultures}

\section{Source}

Culture of HT29 human CER cells.

Culture of LIM1215 cell lines and xenograft mouse model.

Paired tumoral cells of primary CRC and lymph node metastasis.

Procedure

Microvesicles collection by ultracentrifugation; MS/MS analysis.

Culture in $1 \%$ ITS, 24h; 39 glycoproteins identified, among those xenograft minced in PBS, 1h; CDH17, LGALS3BP, and PTK7 were found both in LC-MS/MS analysis.

Culture of Colo205 and Serum-free CM, collected in SW480 cell lines.

Culture of Colo205, SW620 and SW480 cell lines.

Culture of KM12SM and $\mathrm{KM} 12 \mathrm{C}$ colorectal cancer cells

$$
20
$$

Serum-free CM, collected in 20h; LC-MS/MS analysis.

24h: MALDI-TOF/TOF.

Serum-free $\mathrm{CM}$, collected in 24h: MALDI-TOF/TOF and LC$\mathrm{MS} / \mathrm{MS}$ analysis.
Evidence

Ref.

Identification of proteins involved in MV [125 formation and tumorigenesis. vitro and in the interstitial fluids. Two candidate proteins (TFF3, GDF15) selected as biomarkers for the prediction of CRC [123 metastasis.

CRMP-2 was found in CRC secretome; plasma [124 levels were significantly higher in CRC patients. ]

109 unique proteins detected in CRC cell lines [130 secretome. 


\section{cell tumor and stroma cell co-cultures}

Co-culture of colon cancer cells and CAFs.
Co-culture in serum-free media, 2 days; LC-MS/MS analysis.
Collagen type XII selected as dedifferentiation [132 marker of myofibroblasts and/or cancer cells.

\section{tissue secretome}

Paired primary colon cancer ECM decellularization by ADAMs and MMPs found solely in primary colon and liver metastasis vs. sequential extractions; LC- tumor; TIMP1 secreted by both primary cancer normal tissues. MS/MS analysis.

Paired plasma and xenograft- Interstitial fluids collected in derived secretome; PBS, 1h; glycoproteins comparison with cell line enrichment and LC-MS/MS secretome. analysis.

Paired CRC (stages I,II) and normal colorectal tissues from 9 patients.
Pieces of $1-3 \mathrm{~mm} 3$ in serumfree $\mathrm{CM}, 2 \mathrm{~h}$; lectin-based enrichment; LC-MS/MS analysis.

Paired tumor and normal colon mucosa from 4 patients.

Pieces of $1 \mathrm{~mm} 3$ in PBS, $1 \mathrm{~h}$; LC-MS/MS analysis. and liver metastasis.
39 glycoproteins were identified in cell lines secretome, five of them were confirmed in [126 xenograft model.

Among the differentially secreted proteins there are several proteins from fibulin, serpine and peptidase S1 families. $[128$ changes in cancer tissues secretome. 
these biomarkers were moderately accurate $(A \cup C=0.884)$ in the discrimination of patients with CRC and controls with a discrete sensitivity (60\%), but a high specificity (95\%) [131].

Tissue secretome is also an important biomarker source. From a proteomic-based analysis, two different approaches are proposed in literature: the first recovered the tissue secretome by protein passive diffusion from the tissue biopsies into PBS solution [126-128]. In the second, the tissue is subjected to a sequential extraction procedure and the ECM scaffold is finally totally digested before the mass spectrometry analysis [45].

As an example of the first-cited protocol, the label-free quantitative proteomics approach has been used to find secreted biomarkers useful for the detection of lymph node metastasis [123] in paired normal/tumor colon tissue of 4 patients. More than one hundred of candidate biomarkers were obtained by the analysis of differentially abundant proteins ( $>1.5$-fold change). Among these, two peculiar proteins have been selected and quantified in serum samples of a larger cohort of patients, the trefoil factor 3 (TFF3) and the GDF15.

The second protocol has been proposed by Naba et al. The paired analysis of metastatic CRC and its hepatic metastasis has been performed [45] using an ECM enrichment procedure based on the cells lysis and sequential extraction of intracellular components. This procedure highlighted some differences in the secreted proteins and, in particular, most of ECM-remodeling enzymes such as: the ADAM 9, 10 and the MMP-1, 2, 9, 11, 12 and LOXL1. These molecules have been identified exclusively in the primary colon tumor secretome. Despite these promising findings, it is still to investigate the impact of the sequential extraction procedure on the possible loss of low molecular weight secreted factors, such as chemokines, growth factors and cytokines. For instance, among the detected proteins the lack of interleukin-7, which is known to be secreted by colorectal cancer cells to promote the expansion of tumor infiltrating lymphocytes [134], could be ascribed to the aggressiveness of the sequential extraction procedure.

\section{Conclusions and future perspectives}

The idea that changes in ECM architecture may allow cancer development and progression is quite new, and the possibility that these changes could be used as diagnostic or therapeutic tools in cancer treatment is still poorly investigated. For instance, the desmoplastic reaction characterized by Collagen I deposition and altered Collagen IV distribution can directly affects the tumor response to treatment. This change in collagen composition has direct influence on the 
tumor cell survival and resistance to 5-fluorouracil (5-FU), camptothecin and etoposide [135-136]. Conti et al. demonstrated in 3 human CRC cell lines (HT-29, KM12SM and KM12c) that cells cultured in presence of wild type Collagen IV and newly deposited fibrillar Collagen I differently react to therapy. A significant alteration in apoptosis in response to 5-FU has been effectively observed in cultures on fibrillar collagen compared to Collagen IV, and this change has been related to an integrin-mediated mechanism [135]. Moreover, the earlier study of Kouniavsky et al. [136] revealed that tumoral cells cultured onto both single protein layers and ECM-derived layers significantly change their response to chemotherapy. The stroma-derived ECM, and in particular the fibroblast-derived ECM, rendered the LiM6 cell lines more sensitive to the 5-FU. On the contrary, the same fibroblast-derived ECM showed a protective effect on LiM6 cell lines against the etoposide-induced apoptosis. The colon cell lines cultured on fibroblast ECM-layers showed increased expression of two key anti-apoptotic proteins: the bcl-2 and the bcl-x(L). Nevertheless, a direct correlation between the ECM components (are they structural or secreted protein) and bcl2 and $b c l-x(L)$ expression is still lacking [136]. These data suggest a more complex role of ECM and probably the changes in terms of tissue stiffness and 3D organization take part of this process: the tumor stroma is typically stiffer than normal stroma, depending indeed on the substitution of physiological ECM components with other proteins that dramatically change the tumor microenvironment. For example, in the breast cancer, affected tissues can be 10 times stiffer than normal tissues $[11,137]$. In CRC, the stiffness changes and its implication of YAP and TAZ in tumor progression was yet demonstrated [138], but only TAZ has been found to be a prognostic marker after a screening of YAP, TAZ and two downstream target genes in two independent CRC patient cohorts comprising 522 patients [139].

In conclusion, tumor stroma could appear to be a good candidate target for cancer treatment, since it promotes cancer progression, growth and aggressiveness. However, some recent studies demonstrated that inhibition of the stroma reorganization and alignment through drugs or genetic engineering, accelerates tumor growth and decrease survival [140-141]. This suggests that stroma possess a more complex role in cancer homeostasis and progression. For this reason, it will be of paramount importance to analyze in depth the role of cancer matrix composition and architecture to elucidate the mechanisms by which an aligned and stiff ECM can modulate tumor progression and aggressiveness. Once a better understanding of these mechanisms will be gained, new studies should be addressed to find, among the involved proteins 
and pathways, new targets suitable for cancer treatment beside to helpful markers predictive for the patients' response to therapy. 


\section{References:}

[1] Ferlay J., Soerjomataram I., Ervik M., Dikshit R., Eser S., Mathers C., et al. GLOBOCAN 2012 v1.0, Cancer Incidence and Mortality Worldwide: IARC CancerBase No. 11 [Internet]. 2012(09/04/2015): URL: http://globocan.iarc.fr/ia/world/atlas.html

[2] Cancer.Net Editorial Board. Colorectal Cancer. 2012: URL: http://www.cancer.net/cancertypes/colorectal-cancer

[3] UICC. TNM. 2015: URL: http://www.uicc.org/resources/tnm

[4] Radisky D, Muschler J, Bissell MJ. Order and Disorder: The Role of Extracellular Matrix in Epithelial Cancer. Cancer investigation 2002; 20(1): 139-153

[5] Lu P, Weaver VM, Werb Z. The extracellular matrix: A dynamic niche in cancer progression. The Journal of Cell Biology 2012; 196(4): 395-406

[6] Xie K, Abbruzzese JL. Developmental biology informs cancer: the emerging role of the hedgehog signaling pathway in upper gastrointestinal cancers. Cancer Cell 2003; 4(4): 245-247

[7] Radtke F, Clevers H. Self-renewal and cancer of the gut: two sides of a coin. Science 2005; 307(5717): 1904-1909

[8] Whiteside TL. The tumor microenvironment and its role in promoting tumor growth. Oncogene 2008; 27(45): 5904-5912

[9] Sternlicht MD, Lochter A, Sympson CJ, Huey B, Rougier JP, Gray JW, et al. The stromal proteinase MMP3/stromelysin-1 promotes mammary carcinogenesis. Cell 1999; 98(2): 137-146

[10] Paszek MJ, Zahir N, Johnson KR, Lakins JN, Rozenberg GI, Gefen A, et al. Tensional homeostasis and the malignant phenotype. Cancer Cell 2005; 8(3): 241-254

[11] Levental KR, Yu H, Kass L, Lakins JN, Egeblad M, Erler JT, et al. Matrix crosslinking forces tumor progression by enhancing integrin signaling. Cell 2009; 139(5): 891-906

[12] Lu P, Weaver VM, Werb Z. The extracellular matrix: a dynamic niche in cancer progression. J Cell Biol 2012; 196(4): 395-406

[13] Simon-Assmann P, Simo P, Bouziges F, Haffen K, Kedinger M. Synthesis of basement membrane proteins in the small intestine. Digestion 1990; 46 Suppl 2: 12-21

[14] Simon-Assmann P, Kedinger M, De Arcangelis A, Rousseau V, Simo P. Extracellular matrix components in intestinal development. Experientia 1995; 51(9-10): 883-900

[15] Worthley DL, Giraud AS, Wang TC. The extracellular matrix in digestive cancer. Cancer Microenviron 2010; 3(1): 177-185

[16] Tlsty TD, Hein PW. Know thy neighbor: stromal cells can contribute oncogenic signals. Curr Opin Genet Dev 2001; 11(1): 54-59

[17] Mueller MM, Peter W, Mappes M, Huelsen A, Steinbauer H, Boukamp P, et al. Tumor progression of skin carcinoma cells in vivo promoted by clonal selection, mutagenesis, and autocrine growth regulation by granulocyte colony-stimulating factor and granulocyte-macrophage colony-stimulating factor. Am J Pathol 2001; 159(4): 1567-1579 
[18] Tauro BJ, Greening DW, Mathias RA, Mathivanan S, Ji H, Simpson RJ. Two distinct populations of exosomes are released from LIM1863 colon carcinoma cell-derived organoids. Mol Cell Proteomics 2013; 12(3): 587-598

[19] Kharaziha P, Ceder S, Li Q, Panaretakis T. Tumor cell-derived exosomes: a message in a bottle. Biochim Biophys Acta 2012; 1826(1): 103-111

[20] Nickel W, Rabouille C. Mechanisms of regulated unconventional protein secretion. Nat Rev Mol Cell Biol 2009; 10(2): 148-155

[21] Naba A, Clauser KR, Hoersch S, Liu H, Carr SA, Hynes RO. The matrisome: in silico definition and in vivo characterization by proteomics of normal and tumor extracellular matrices. Mol Cell Proteomics 2012; 11(4): M111 014647

[22] Provenzano PP, Eliceiri KW, Campbell JM, Inman DR, White JG, Keely PJ. Collagen reorganization at the tumor-stromal interface facilitates local invasion. Bmc Med 2006; 4

[23] Goetz JG, Minguet S, Navarro-Lerida I, Lazcano JJ, Samaniego R, Calvo E, et al. Biomechanical remodeling of the microenvironment by stromal caveolin-1 favors tumor invasion and metastasis. Cell 2011; 146(1): 148-163

[24] Stadler E, Dziadek M. Extracellular Matrix Penetration by Epithelial Cells Is Influenced by Quantitative Changes in Basement Membrane Components and Growth Factors. Experimental Cell Research 1996; 229(2): 360-369

[25] Tlsty TD, Coussens LM. TUMOR STROMA AND REGULATION OF CANCER DEVELOPMENT. Annual Review of Pathology: Mechanisms of Disease 2006; 1(1): 119-150

[26] Kalluri R. Basement membranes: structure, assembly and role in tumour angiogenesis. Nat Rev Cancer 2003; 3(6): 422-433

[27] Rousselle P, Beck K. Laminin 332 processing impacts cellular behavior. Cell Adhesion \& Migration 2013; 7(1): 122-134

[28] Guess CM, LaFleur BJ, Weidow BL, Quaranta V. A Decreased Ratio of Laminin-332 $\beta 3$ to Y2 Subunit mRNA is Associated with Poor Prognosis in Colon Cancer. Cancer Epidem Biomar 2009; 18(5): 1584-1590

[29] Tsuruta D, Kobayashi H, Imanishi H, Sugawara K, Ishii M, Jones JCR. Laminin-332-Integrin Interaction: A Target For Cancer Therapy? Current medicinal chemistry 2008; 15(20): 1968-1975

[30] Mylonas CC, Lazaris AC. Colorectal cancer and basement membranes: clinicopathological correlations. Gastroenterol Res Pract 2014; 2014: 580159

[31] Delektorskaya VV, Kushlinskii NE. Clinical Significance of the Content of Biomolecular Markers in Invasive Front of Colon Carcinomas. Bull Exp Biol Med 2011; 150(3): 368-371

[32] Lazaris AC, Tzoumani AN, Thimara I, Theodoropoulos GE, Thomopoulou G, Dicoglou C, et al. Immunohistochemical assessment of basement membrane components in colorectal cancer: Prognostic implications. Journal of Experimental \& Clinical Cancer Research 2003; 22(4): 599-606

[33] J. Adur, M. Bianchi, V.B. Pelegati, S. Viale, M. F. Izaguirre, H.F. Carvalho, et al. Colon Adenocarcinoma Diagnosis in Human Samples by Multicontrast Nonlinear Optical Microscopy of Hematoxylin and Eosin Stained Histological Sections. Journal of Cancer Therapy 2014; 5(13) 
[34] Birk JW, Tadros M, Moezardalan K, Nadyarnykh O, Forouhar F, Anderson J, et al. Second harmonic generation imaging distinguishes both high-grade dysplasia and cancer from normal colonic mucosa. Dig Dis Sci 2014; 59(7): 1529-1534

[35] Bröker MEE, Lalmahomed ZS, Roest HP, van Huizen NA, Dekker LM, Calame W, et al. Collagen Peptides in Urine: A New Promising Biomarker for the Detection of Colorectal Liver Metastases. PLoS One 2013; 8(8): e70918

[36] Seibel MJ. Biochemical Markers of Bone Turnover Part I: Biochemistry and Variability. The Clinical biochemist Reviews / Australian Association of Clinical Biochemists 2005; 26(4): 97-122

[37] Zou X, Feng B, Dong T, Yan G, Tan B, Shen H, et al. Up-regulation of type I collagen during tumorigenesis of colorectal cancer revealed by quantitative proteomic analysis. Journal of Proteomics 2013; 94(0): 473-485

[38] Sheth KR, Clary BM. Management of Hepatic Metastases from Colorectal Cancer. Clinics in Colon and Rectal Surgery 2005; 18(3): 215-223

[39] Herbst H, Frey A, Heinrichs O, Milani S, Bechstein WO, Neuhaus P, et al. Heterogeneity of liver cells expressing procollagen types I and IV in vivo. Histochem Cell Biol 1997; 107(5): 399-409

[40] Hirayama C, Suzuki H, Takada A, Fujisawa K, Tanikawa K, Igarashi S. Serum type IV collagen in various liver diseases in comparison with serum $7 \mathrm{~S}$ collagen, laminin, and type III procollagen peptide. J Gastroenterol 1996; 31(2): 242-248

[41] Offerhaus GJ, Giardiello FM, Bruijn JA, Stijnen T, Molyvas EN, Fleuren GJ. The value of immunohistochemistry for collagen IV expression in colorectal carcinomas. Cancer 1991; 67(1): 99-105

[42] Lazaris A, Tzoumani AN, Thimara I, Theodoropoulos GE, Thomopoulou G, Dicoglou C, et al. Immunohistochemical assessment of basement membrane components in colorectal cancer: prognostic implications. J Exp Clin Cancer Res 2003; 22(4): 599-606

[43] Nyström H, Naredi P, Hafström L, Sund M. Type IV collagen as a tumour marker for colorectal liver metastases. European Journal of Surgical Oncology (EJSO) 2011; 37(7): 611-617

[44] Gulubova MV, Vlaykova TI. Significance of tenascin-C, fibronectin, laminin, collagen IV, alpha5beta1 and alpha9beta1 integrins and fibrotic capsule formation around liver metastases originating from cancers of the digestive tract. Neoplasma 2006; 53(5): 372-383

[45] Naba A, Clauser KR, Whittaker CA, Carr SA, Tanabe KK, Hynes RO. Extracellular matrix signatures of human primary metastatic colon cancers and their metastases to liver. BMC Cancer 2014; 14: 518

[46] Yang HY, Kwon J, Park HR, Kwon SO, Park YK, Kim HS, et al. Comparative proteomic analysis for the insoluble fractions of colorectal cancer patients. J Proteomics 2012; 75(12): 3639-3653

[47] Le QT, Harris J, Magliocco AM, Kong CS, Diaz R, Shin B, et al. Validation of Lysyl Oxidase As a Prognostic Marker for Metastasis and Survival in Head and Neck Squamous Cell Carcinoma: Radiation Therapy Oncology Group Trial 90-03. Journal of Clinical Oncology 2009; 27(26): 4281-4286

[48] Baker AM, Cox TR, Bird D, Lang G, Murray GI, Sun XF, et al. The Role of Lysyl Oxidase in SRCDependent Proliferation and Metastasis of Colorectal Cancer. J Natl Cancer I 2011; 103(5): 407-424

[49] Baker AM, Bird D, Lang G, Cox TR, Erler JT. Lysyl oxidase enzymatic function increases stiffness to drive colorectal cancer progression through FAK. Oncogene 2013; 32(14): 1863-1868 
[50] Gieni RS, Hendzel MJ. Mechanotransduction from the ECM to the genome: are the pieces now in place? J Cell Biochem 2008; 104(6): 1964-1987

[51] Aragona M, Panciera T, Manfrin A, Giulitti S, Michielin F, Elvassore N, et al. A Mechanical Checkpoint Controls Multicellular Growth through YAP/TAZ Regulation by Actin-Processing Factors. Cell 2013; 154(5): 1047-1059

[52] Azzolin L, Panciera T, Soligo S, Enzo E, Bicciato S, Dupont S, et al. YAP/TAZ incorporation in the beta-catenin destruction complex orchestrates the Wnt response. Cell 2014; 158(1): 157-170

[53] Dupont S, Morsut L, Aragona M, Enzo E, Giulitti S, Cordenonsi M, et al. Role of YAP/TAZ in mechanotransduction. Nature 2011; 474(7350): 179-183

[54] Zhao B, Wei X, Li W, Udan RS, Yang Q, Kim J, et al. Inactivation of YAP oncoprotein by the Hippo pathway is involved in cell contact inhibition and tissue growth control. Gene Dev 2007; 21(21): 27472761

[55] Lei QY, Zhang H, Zhao B, Zha ZY, Bai F, Pei XH, et al. TAZ promotes cell proliferation and epithelialmesenchymal transition and is inhibited by the hippo pathway. Molecular and Cellular Biology 2008; 28(7): 2426-2436

[56] Zhang X, George J, Deb S, Degoutin JL, Takano EA, Fox SB, et al. The Hippo pathway transcriptional co-activator, YAP, is an ovarian cancer oncogene. Oncogene 2011; 30(25): 2810-2822

[57] Muramatsu T, Imoto I, Matsui T, Kozaki K, Haruki S, Sudol M, et al. YAP is a candidate oncogene for esophageal squamous cell carcinoma. Carcinogenesis 2011; 32(3): 389-398

[58] Zhao D, Zhi X, Zhou ZM, Chen CS. TAZ antagonizes the WWP1-mediated KLF5 degradation and promotes breast cell proliferation and tumorigenesis. Carcinogenesis 2012; 33(1): 59-67

[59] Lai D, Ho KC, Hao YW, Yang XL. Taxol Resistance in Breast Cancer Cells Is Mediated by the Hippo Pathway Component TAZ and Its Downstream Transcriptional Targets Cyr61 and CTGF. Cancer Research 2011; 71(7): 2728-2738

[60] Zhou Z, Hao Y, Liu N, Raptis L, Tsao MS, Yang X. TAZ is a novel oncogene in non-small cell lung cancer. Oncogene 2011; 30(18): 2181-2186

[61] Zhou DW, Zhang YY, Wu H, Barry E, Yin Y, Lawrence E, et al. Mst1 and Mst2 protein kinases restrain intestinal stem cell proliferation and colonic tumorigenesis by inhibition of Yes-associated protein (Yap) overabundance. P Natl Acad Sci USA 2011; 108(49): E1312-E1320

[62] Rocha B, Calamia V, Casas V, Carrascal M, Blanco FJ, Ruiz-Romero C. Secretome Analysis of Human Mesenchymal Stem Cells Undergoing Chondrogenic Differentiation. Journal of Proteome Research 2014; 13(2): 1045-1054

[63] Thouvenot E, Urbach S, Vigy O, Seveno M, Galeotti N, Nguyen G, et al. Quantitative proteomic analysis reveals protein expression changes in the murine neuronal secretome during apoptosis. J Proteomics 2012; 77: 394-405

[64] Wen YT, Wang JS, Tsai SH, Chuan CN, Wu JJ, Liao PC. Label-free proteomic analysis of environmental acidification-influenced Streptococcus pyogenes secretome reveals a novel acid-induced protein histidine triad protein A (HtpA) involved in necrotizing fasciitis. J Proteomics 2014; 109: 90-103 
[65] Renes J, Rosenow A, Roumans N, Noben JP, Mariman EC. Calorie restriction-induced changes in the secretome of human adipocytes, comparison with resveratrol-induced secretome effects. Biochim Biophys Acta 2014; 1844(9): 1511-1522

[66] Pavlou MP, Diamandis EP. The cancer cell secretome: a good source for discovering biomarkers? J Proteomics 2010; 73(10): 1896-1906

[67] Groblewska M, Mroczko B, Gryko M, Pryczynicz A, Guzińska-Ustymowicz K, Kędra B, et al. Serum levels and tissue expression of matrix metalloproteinase 2 (MMP-2) and tissue inhibitor of metalloproteinases 2 (TIMP-2) in colorectal cancer patients. Tumour Biology 2014; 35(4): 3793-3802

[68] Kahlert C, Pecqueux M, Halama N, Dienemann H, Muley T, Pfannschmidt J, et al. Tumour-sitedependent expression profile of angiogenic factors in tumour-associated stroma of primary colorectal cancer and metastases. Br J Cancer 2014; 110(2): 441-449

[69] Hogan NM, Joyce MR, Murphy JM, Barry FP, O'Brien T, Kerin MJ, et al. Impact of mesenchymal stem cell secreted PAI-1 on colon cancer cell migration and proliferation. Biochem Biophys Res Commun 2013; 435(4): 574-579

[70] Baker EA, Bergin FG, Leaper DJ. Matrix metalloproteinases, their tissue inhibitors and colorectal cancer staging. Br J Surg 2000; 87(9): 1215-1221

[71] Seetoo DQ, Crowe PJ, Russell PJ, Yang JL. Quantitative expression of protein markers of plasminogen activation system in prognosis of colorectal cancer. J Surg Oncol 2003; 82(3): 184-193

[72] Cal S, Lopez-Otin C. ADAMTS proteases and cancer. Matrix Biol 2015; 44-46: 77-85

[73] Gora J, Latajka R. Involvement of cysteine proteases in cancer. Curr Med Chem 2015; 22(8): 944-

957

[74] Said AH, Raufman J-P, Xie G. The Role of Matrix Metalloproteinases in Colorectal Cancer. Cancers 2014; 6(1): 366-375

[75] Chu TY, Yang JT, Huang TH, Liu HW. Crosstalk with cancer-associated fibroblasts increases the growth and radiation survival of cervical cancer cells. Radiat Res 2014; 181(5): 540-547

[76] Giannoni E, Bianchini F, Masieri L, Serni S, Torre E, Calorini L, et al. Reciprocal activation of prostate cancer cells and cancer-associated fibroblasts stimulates epithelial-mesenchymal transition and cancer stemness. Cancer Res 2010; 70(17): 6945-6956

[77] Sierra JR, Corso S, Caione L, Cepero V, Conrotto P, Cignetti A, et al. Tumor angiogenesis and progression are enhanced by Sema4D produced by tumor-associated macrophages. J Exp Med 2008; 205(7): 1673-1685

[78] Kang JC, Chen JS, Lee CH, Chang JJ, Shieh YS. Intratumoral macrophage counts correlate with tumor progression in colorectal cancer. J Surg Oncol 2010; 102(3): 242-248

[79] Zaytseva YY, Elliott VA, Rychahou P, Mustain WC, Kim JT, Valentino J, et al. Cancer cell-associated fatty acid synthase activates endothelial cells and promotes angiogenesis in colorectal cancer.

Carcinogenesis 2014; 35(6): 1341-1351

[80] Carmeliet P, Jain RK. Angiogenesis in cancer and other diseases. Nature 2000; 407(6801): 249-257 
[81] Viloria CG, Obaya AJ, Moncada-Pazos A, Llamazares M, Astudillo A, Capella G, et al. Genetic inactivation of ADAMTS15 metalloprotease in human colorectal cancer. Cancer Res 2009; 69(11): 49264934

[82] Connolly KC, Gabra H, Millwater CJ, Taylor KJ, Rabiasz GJ, Watson JE, et al. Identification of a region of frequent loss of heterozygosity at 11q24 in colorectal cancer. Cancer Res 1999; 59(12): 2806-2809

[83] Sjöblom T, Jones S, Wood LD, Parsons DW, Lin J, Barber TD, et al. The Consensus Coding Sequences of Human Breast and Colorectal Cancers. Science 2006; 314(5797): 268-274

[84] Li Z, Zhang W, Shao Y, Zhang C, Wu Q, Yang H, et al. High-resolution melting analysis of ADAMTS18 methylation levels in gastric, colorectal and pancreatic cancers. Med Oncol 2010; 27(3): 998-1004

[85] Hazen LG, Bleeker FE, Lauritzen B, Bahns S, Song J, Jonker A, et al. Comparative localization of cathepsin B protein and activity in colorectal cancer. J Histochem Cytochem 2000; 48(10): 1421-1430

[86] Chan AT, Baba Y, Shima K, Nosho K, Chung DC, Hung KE, et al. Cathepsin B expression and survival in colon cancer: implications for molecular detection of neoplasia. Cancer Epidemiol Biomarkers Prev 2010; 19(11): 2777-2785

[87] Troy AM, Sheahan K, Mulcahy HE, Duffy MJ, Hyland JM, O'Donoghue DP. Expression of Cathepsin B and $L$ antigen and activity is associated with early colorectal cancer progression. Eur J Cancer 2004; 40(10): 1610-1616

[88] Talieri M, Papadopoulou S, Scorilas A, Xynopoulos D, Arnogianaki N, Plataniotis G, et al. Cathepsin B and cathepsin $D$ expression in the progression of colorectal adenoma to carcinoma. Cancer Lett 2004; 205(1): 97-106

[89] Doxakis A, Maria A, Savvas P, Zafiroula I. Assessment of the Roles of Cathepsins B, H and L in the Progression of Colorectal Cancer. Journal of Cancer Therapy 2013; 4(6B): 1-7

[90] Sunami E, Tsuno N, Osada T, Saito S, Kitayama J, Tomozawa S, et al. MMP-1 is a prognostic marker for hematogenous metastasis of colorectal cancer. Oncologist 2000; 5(2): 108-114

[91] Bendardaf R, Buhmeida A, Ristamaki R, Syrjanen K, Pyrhonen S. MMP-1 (collagenase-1) expression in primary colorectal cancer and its metastases. Scand J Gastroenterol 2007; 42(12): 1473-1478

[92] Dragutinovic VV, Radonjic NV, Petronijevic ND, Tatic SB, Dimitrijevic IB, Radovanovic NS, et al. Matrix metalloproteinase-2 (MMP-2) and -9 (MMP-9) in preoperative serum as independent prognostic markers in patients with colorectal cancer. Mol Cell Biochem 2011; 355(1-2): 173-178

[93] Groblewska M, Mroczko B, Gryko M, Pryczynicz A, Guzinska-Ustymowicz K, Kedra B, et al. Serum levels and tissue expression of matrix metalloproteinase 2 (MMP-2) and tissue inhibitor of metalloproteinases 2 (TIMP-2) in colorectal cancer patients. Tumour Biol 2014; 35(4): 3793-3802

[94] Koskensalo S, Louhimo J, Nordling S, Hagstrom J, Haglund C. MMP-7 as a prognostic marker in colorectal cancer. Tumour Biol 2011; 32(2): 259-264

[95] Zeng ZS, Shu WP, Cohen AM, Guillem JG. Matrix metalloproteinase-7 expression in colorectal cancer liver metastases: evidence for involvement of MMP-7 activation in human cancer metastases. Clin Cancer Res 2002; 8(1): 144-148 
[96] Wu Q, Yang Y, Wu S, Li W, Zhang N, Dong X, et al. Evaluation of the correlation of KAI1/CD82, CD44, MMP7 and beta-catenin in the prediction of prognosis and metastasis in colorectal carcinoma. Diagn Pathol 2015; 10: 176

[97] Araujo RF, Jr., Lira GA, Vilaca JA, Guedes HG, Leitao MC, Lucena HF, et al. Prognostic and diagnostic implications of MMP-2, MMP-9, and VEGF-alpha expressions in colorectal cancer. Pathol Res Pract 2015; 211(1): 71-77

[98] Lee MA, Park JH, Rhyu SY, Oh ST, Kang WK, Kim HN. Wnt3a expression is associated with MMP-9 expression in primary tumor and metastatic site in recurrent or stage IV colorectal cancer. BMC Cancer 2014; 14: 125

[99] Hurst NG, Stocken DD, Wilson S, Keh C, Wakelam MJ, Ismail T. Elevated serum matrix metalloproteinase 9 (MMP-9) concentration predicts the presence of colorectal neoplasia in symptomatic patients. Br J Cancer 2007; 97(7): 971-977

[100] Asano T, Tada M, Cheng S, Takemoto N, Kuramae T, Abe M, et al. Prognostic values of matrix metalloproteinase family expression in human colorectal carcinoma. J Surg Res 2008; 146(1): 32-42

[101] Yang W, Arii S, Gorrin-Rivas MJ, Mori A, Onodera H, Imamura M. Human macrophage metalloelastase gene expression in colorectal carcinoma and its clinicopathologic significance. Cancer 2001; 91(7): 1277-1283

[102] Leeman MF, McKay JA, Murray GI. Matrix metalloproteinase 13 activity is associated with poor prognosis in colorectal cancer. J Clin Pathol 2002; 55(10): 758-762

[103] Foda AA, El-Hawary AK, Abdel-Aziz A. Matrix metalloproteinase-13 expression in the progression of colorectal adenoma to carcinoma : Matrix metalloproteinase-13 expression in the colorectal adenoma and carcinoma. Tumour Biol 2014; 35(6): 5653-5658

[104] Foda AA, El-Hawary AK, Abdel-Aziz A. Differential expression of matrix metalloproteinase-13 in mucinous and nonmucinous colorectal carcinomas. Ann Diagn Pathol 2013; 17(4): 347-351

[105] Yang B, Gao J, Rao Z, Shen Q. Clinicopathological significance and prognostic value of MMP-13 expression in colorectal cancer. Scand J Clin Lab Invest 2012; 72(6): 501-505

[106] MarkI B, Renk I, Oruzio DV, Jahnig H, Schenkirsch G, Scholer C, et al. Tumour budding, uPA and PAI1 are associated with aggressive behaviour in colon cancer. J Surg Oncol 2010; 102(3): 235-241

[107] Mazzoccoli G, Pazienza V, Panza A, Valvano MR, Benegiamo G, Vinciguerra M, et al. ARNTL2 and SERPINE1: potential biomarkers for tumor aggressiveness in colorectal cancer. J Cancer Res Clin Oncol 2012; 138(3): 501-511

[108] Naitoh H, Eguchi $Y$, Ueyama $H$, Kodama $M$, Hattori T. Localization of urokinase-type plasminogen activator, plasminogen activator inhibitor-1, 2 and plasminogen in colon cancer. Jpn J Cancer Res 1995; 86(1): 48-56

[109] Langenskiöld M, Holmdahl L, Angenete E, Falk P, Nordgren S, Ivarsson ML. Differential Prognostic Impact of UPA and PAI-1 in Colon and Rectal Cancer. Tumor Biology 2009; 30(4): 210-220

[110] Halamkova J, Kiss I, Pavlovsky Z, Tomasek J, Jarkovsky J, Cech Z, et al. Clinical significance of the plasminogen activator system in relation to grade of tumor and treatment response in colorectal carcinoma patients. Neoplasma 2011; 58(5): 377-385 
[111] Gandolfo GM, Conti L, Vercillo M. Fibrinolysis components as prognostic markers in breast cancer and colorectal carcinoma. Anticancer Res 1996; 16(4B): 2155-2159

[112] Oblak I, Anderluh F, Velenik V, Mozina B, Ocvirk J, Ciric E, et al. Differences in plasma TIMP-1 levels between healthy people and patients with rectal cancer stage II or III. Radiol Oncol 2011; 45(3): 209-212

[113] Holten-Andersen MN, Christensen IJ, Nielsen HJ, Stephens RW, Jensen V, Nielsen OH, et al. Total levels of tissue inhibitor of metalloproteinases 1 in plasma yield high diagnostic sensitivity and specificity in patients with colon cancer. Clin Cancer Res 2002; 8(1): 156-164

[114] Holten-Andersen MN, Hansen U, Brunner N, Nielsen HJ, Illemann M, Nielsen BS. Localization of tissue inhibitor of metalloproteinases 1 (TIMP-1) in human colorectal adenoma and adenocarcinoma. Int J Cancer 2005; 113(2): 198-206

[115] Moran A, Iniesta P, Garcia-Aranda C, De Juan C, Diaz-Lopez A, Sanchez-Pernaute A, et al. Clinical relevance of MMP-9, MMP-2, TIMP-1 and TIMP-2 in colorectal cancer. Oncol Rep 2005; 13(1): 115-120

[116] Lin $H$, Zhang $Y$, Wang $H$, Xu D, Meng $X$, Shao $Y$, et al. Tissue inhibitor of metalloproteinases-3 transfer suppresses malignant behaviors of colorectal cancer cells. Cancer Gene Ther 2012; 19(12): 845851

[117] Qin S, Zhu Y, Ai F, Li Y, Bai B, Yao W, et al. MicroRNA-191 correlates with poor prognosis of colorectal carcinoma and plays multiple roles by targeting tissue inhibitor of metalloprotease 3 . Neoplasma 2014; 61(1): 27-34

[118] Zeng Z, Sun Y, Shu W, Guillem JG. Tissue inhibitor of metalloproteinase-3 is a basement membrane-associated protein that is significantly decreased in human colorectal cancer. Dis Colon Rectum 2001; 44(9): 1290-1296

[119] Hilska M, Roberts PJ, Collan YU, Laine VJ, Kossi J, Hirsimaki P, et al. Prognostic significance of matrix metalloproteinases-1, $-2,-7$ and -13 and tissue inhibitors of metalloproteinases-1, $-2,-3$ and -4 in colorectal cancer. Int J Cancer 2007; 121(4): 714-723

[120] de Bruin PA, Griffioen G, Verspaget HW, Verheijen JH, Lamers CB. Plasminogen activators and tumor development in the human colon: activity levels in normal mucosa, adenomatous polyps, and adenocarcinomas. Cancer Res 1987; 47(17): 4654-4657

[121] Baker EA, Bergin FG, Leaper DJ. Plasminogen activator system, vascular endothelial growth factor, and colorectal cancer progression. Molecular Pathology 2000; 53(6): 307-312

[122] Baker EA, Leaper DJ. The plasminogen activator and matrix metalloproteinase systems in colorectal cancer: relationship to tumour pathology. Eur J Cancer 2003; 39(7): 981-988

[123] Xue H, Lu B, Zhang J, Wu M, Huang $Q, W u$, et al. Identification of serum biomarkers for colorectal cancer metastasis using a differential secretome approach. J Proteome Res 2010; 9(1): 545-555

[124] Wu CC, Chen HC, Chen SJ, Liu HP, Hsieh YY, Yu CJ, et al. Identification of collapsin response mediator protein-2 as a potential marker of colorectal carcinoma by comparative analysis of cancer cell secretomes. Proteomics 2008; 8(2): 316-332

[125] Choi DS, Lee JM, Park GW, Lim HW, Bang JY, Kim YK, et al. Proteomic analysis of microvesicles derived from human colorectal cancer cells. Journal of Proteome Research 2007; 6(12): 4646-4655 
[126] Bernhard OK, Greening DW, Barnes TW, Ji H, Simpson RJ. Detection of cadherin-17 in human colon cancer LIM1215 cell secretome and tumour xenograft-derived interstitial fluid and plasma. Biochim Biophys Acta 2013; 1834(11): 2372-2379

[127] Yao L, Lao W, Zhang Y, Tang X, Hu X, He C, et al. Identification of EFEMP2 as a serum biomarker for the early detection of colorectal cancer with lectin affinity capture assisted secretome analysis of cultured fresh tissues. J Proteome Res 2012; 11(6): 3281-3294

[128] de Wit M, Kant H, Piersma SR, Pham TV, Mongera S, van Berkel MPA, et al. Colorectal cancer candidate biomarkers identified by tissue secretome proteome profiling. Journal of Proteomics 2014; 99: 26-39

[129] Caccia D, Dugo M, Callari M, Bongarzone I. Bioinformatics tools for secretome analysis. Biochim Biophys Acta 2013; 1834(11): 2442-2453

[130] Wu CC, Hsu CW, Chen CD, Yu CJ, Chang KP, Tai DI, et al. Candidate Serological Biomarkers for Cancer Identified from the Secretomes of 23 Cancer Cell Lines and the Human Protein Atlas. Molecular \& Cellular Proteomics 2010; 9(6): 1100-1117

[131] Barderas R, Mendes M, Torres S, Bartolome RA, Lopez-Lucendo M, Villar-Vazquez R, et al. In-depth characterization of the secretome of colorectal cancer metastatic cells identifies key proteins in cell adhesion, migration, and invasion. Mol Cell Proteomics 2013; 12(6): 1602-1620

[132] Karagiannis GS, Petraki C, Prassas I, Saraon P, Musrap N, Dimitromanolakis A, et al. Proteomic signatures of the desmoplastic invasion front reveal collagen type XII as a marker of myofibroblastic differentiation during colorectal cancer metastasis. Oncotarget 2012; 3(3): 267-285

[133] Eichelbaum K, Winter M, Diaz MB, Herzig S, Krijgsveld J. Selective enrichment of newly synthesized proteins for quantitative secretome analysis. Nat Biotech 2012; 30(10): 984-990

[134] Maeurer MJ, Walter W, Martin D, Zitvogel L, Elder E, Storkus W, et al. Interleukin-7 (IL-7) in colorectal cancer: IL-7 is produced by tissues from colorectal cancer and promotes preferential expansion of tumour infiltrating lymphocytes. Scand J Immunol 1997; 45(2): 182-192

[135] Conti JA, Kendall TJ, Bateman A, Armstrong TA, Papa-Adams A, Xu Q, et al. The Desmoplastic Reaction Surrounding Hepatic Colorectal Adenocarcinoma Metastases Aids Tumor Growth and Survival via alpha(v) Integrin Ligation. Clinical Cancer Research 2008; 14(20): 6405-6413

[136] Kouniavsky G, Khaikin M, Zvibel I, Zippel D, Brill S, Halpern Z, et al. Stromal extracellular matrix reduces chemotherapy-induced apoptosis in colon cancer cell lines. Clin Exp Metastasis 2002; 19(1): 55-60

[137] Lopez JI, Kang I, You WK, McDonald DM, Weaver VM. In situ force mapping of mammary gland transformation. Integr Biol (Camb) 2011; 3(9): 910-921

[138] Wang L, Shi SJ, Guo ZY, Zhang X, Han SX, Yang AG, et al. Overexpression of YAP and TAZ Is an Independent Predictor of Prognosis in Colorectal Cancer and Related to the Proliferation and Metastasis of Colon Cancer Cells. PLoS One 2013; 8(6)

[139] Yuen HF, McCrudden CM, Huang YH, Tham JM, Zhang XQ, Zeng Q, et al. TAZ Expression as a Prognostic Indicator in Colorectal Cancer. PLoS One 2013; 8(1)

[140] Ozdemir BC, Pentcheva-Hoang T, Carstens JL, Zheng XF, Wu CC, Simpson TR, et al. Depletion of Carcinoma-Associated Fibroblasts and Fibrosis Induces Immunosuppression and Accelerates Pancreas Cancer with Reduced Survival. Cancer Cell 2014; 25(6): 719-734 
[141] Rhim AD, Oberstein PE, Thomas DH, Mirek ET, Palermo CF, Sastra SA, et al. Stromal Elements Act to Restrain, Rather Than Support, Pancreatic Ductal Adenocarcinoma. Cancer Cell 2014; 25(6): 735-747 